\title{
Meiogyne oligocarpa (Annonaceae), a new species from Yunnan, China
}

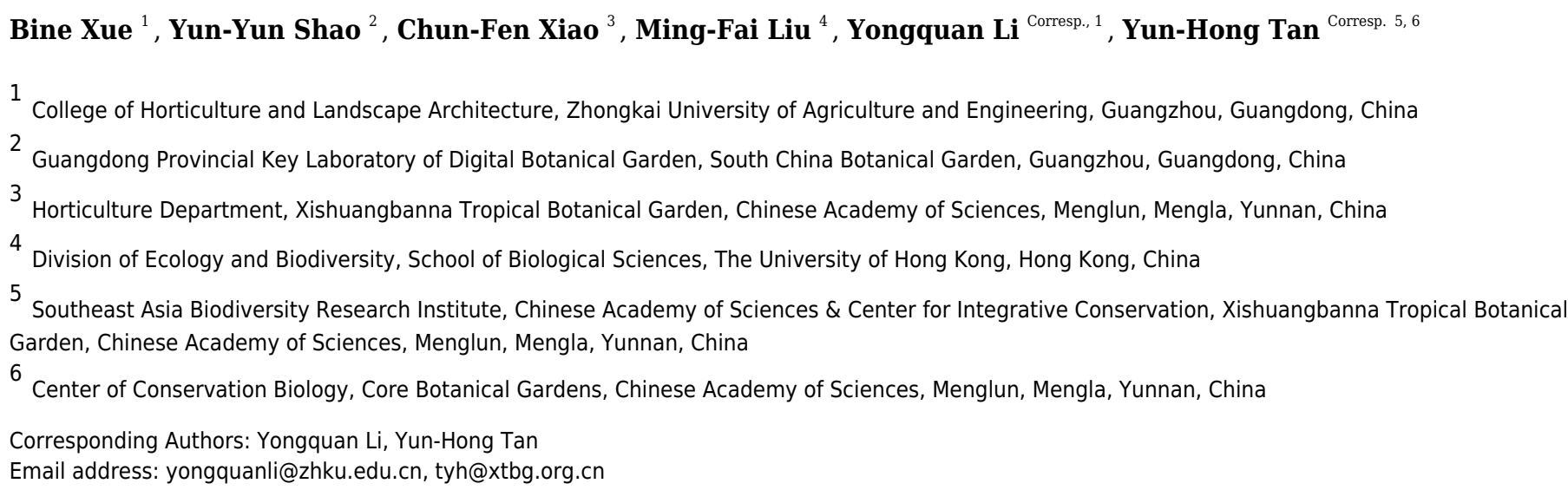

Meiogyne oligocarpa sp. nov. (Annonaceae) is described from Yunnan Province in Southwest China. It is easily distinguished from all previously described Meiogyne species by the possession of up to four carpels per flower, its bilobed, sparsely hairy stigma, biseriate ovules and cylindrical monocarps with a beaked apex. A phylogenetic analysis was conducted to confirm the placement of this new species within Meiogyne. Meiogyne oligocarpa represents the second species of Meiogyne in China: a key to the species of Meiogyne in China is provided to distinguish it from Meiogyne hainanensis. Paraffin sectioning was undertaken to study the anatomy of the corrugations on the inner petals of Meiogyne oligocarpa to verify whether they are glandular. 
${ }^{1}$ College of Horticulture and Landscape Architecture, Zhongkai University of Agriculture and Engineering, Guangzhou 510225, Guangdong, China

$7 \quad{ }^{2}$ Guangdong Provincial Key Laboratory of Digital Botanical Garden, South China Botanical

8 Garden, Chinese Academy of Sciences, Guangzhou 510650, China

$9{ }^{3}$ Horticulture Department, Xishuangbanna Tropical Botanical Garden, Chinese Academy of

10 Sciences, Menglun, Mengla, Yunnan 666303, P.R. China

$11{ }^{4}$ Division of Ecology and Biodiversity, School of Biological Sciences, The University of Hong

12 Kong, Hong Kong, China

13 5Southeast Asia Biodiversity Research Institute, Chinese Academy of Sciences \& Center for 14 Integrative Conservation, Xishuangbanna Tropical Botanical Garden, Chinese Academy of

15 Sciences, Menglun, Mengla, Yunnan 666303, P.R. China

$16{ }^{6}$ Center of Conservation Biology, Core Botanical Gardens, Chinese Academy of Sciences,

17 Menglun, Mengla, Yunnan 666303, P.R. China

\section{Abstract}

Meiogyne oligocarpa sp. nov. (Annonaceae) is described from Yunnan Province in Southwest

Corresponding authors:

Yun-Hong Tan, tyh@xtbg.ac.cn

Yongquan Li, yongquanli@zhku.edu.cn China. It is easily distinguished from all previously described Meiogyne species by the possession of up to four carpels per flower, its bilobed, sparsely hairy stigma, biseriate ovules and cylindrical monocarps with a beaked apex. A phylogenetic analysis was conducted to confirm the placement of this new species within Meiogyne. Meiogyne oligocarpa represents the second species of Meiogyne in China: a key to the species of Meiogyne in China is provided to distinguish it from Meiogyne hainanensis. Paraffin sectioning was undertaken to study the anatomy of the corrugations on the inner petals of Meiogyne oligocarpa to verify whether they are glandular.

Subjects Biodiversity, Plant Science, Taxonomy

Keywords Meiogyne, molecular phylogeny, taxonomy, Yunnan, China 


\section{Introduction}

38 The Annonaceae is the most genus-rich and species-rich family in Magnoliales, with ca. 110 genera and ca. 2400 species (Chaotrou et al., 2012; Guo et al., 2017; Xue et al. 2020). Meiogyne Miq. is a medium-sized genus in the tribe Miliuseae, subfam. Malmeoideae, currently comprising 32 species of trees or shrubs, distributed in wet tropical lowland and lower montane rainforests across South-east Asia and the western Pacific (Thomas et al., 2012; Xue et al., 2014, 2017; Turner \& Utteridge, 2015; Johnson et al., 2019). It has recently been expanded following the inclusion of species formerly classified in Ancana F. Muell., Ararocarpus Scheff., Guamia Merr., Polyaulax Backer, Fitzalania F. Muell., Chieniodendron Tsiang \& Li, Oncodostigma Diels and four Fijian Polyalthia species (van Heusden, 1994; Thomas et al., 2012; Xue et al., 2014, 2017; Turner and Utteridge, 2015). Among those genera, the name Fitzalania (Mueller, 1863) antedates that of Meiogyne (Miquel, 1865); Chaowasku et al. (2011) consequently proposed conservation of the latter name (subsequently accepted by the Nomenclature Committee for Vascular Plants: Applequist, 2012).

Yunnan Province is located in southwestern China and harbors more than 19,000 plant taxa, accounting for over 50\% of China's overall floristic diversity (Qian et al., 2020). Plant diversity in Yunnan faces continuous threats with the deterioration of ecology and environment, however. In order to constrain the rapid loss of biodiversity, the Chinese Academy of Science and Yunnan Provincial government jointly launched a project named Tropical Plant Resource Conservation and Sustainable Use from 2000 to 2004. In this project, more than 6,000 plant species collected from tropical areas of China and nearby countries were preserved in 35 living collections in Xishuangbanna Tropical Botanical Garden. These include about 100 Annonaceae collections, among which twelve small trees have been continuously flowering and fruiting in recent years. These treelets were propagated from 20 seeds collected from one unidentified Annonaceae tree in He-kou County, Yunnan Province in 2001 by a field collection team leading by Professor Guo-Da Tao. The flower morphology indicates that it belongs to Meiogyne, but it differs from all previously described species. It is readily distinguished from other Meiogyne species by a combination of the following characters: flowers with bilobed stigmas, up to four carpels per flower, ovaries with ovules attached in two rows and cylindrical monocarps with a beaked apex. Morphological comparisons and phylogenetic analyses based on seven chloroplast regions indicate that the treelets represent a hitherto undescribed species, which we describe and name here as Meigoyne oligocarpa.

Meiogyne is characterized by inner petals with a longitudinally grooved or verrucose base to the adaxial surface and innermost stamens with tongue-shaped apical prolongations (van Heusden, 1994; Thomas et al., 2012; Xue et al., 2014; Johnson et al., 2019). The elaborate inner petal corrugations are synapomorphic for Meiogyne, and have often been referred to as "glands" (van Heusden, 1992; Saunders, 2010), although glandular function has never been confirmed as no liquid secretions have been observed (Xue et al., 2017). Shao \& Xu similarly failed to observe apertures for secretion on the surface of the corrugations ("strumae") on inner petals of Meiogyne hainanensis (as "Oncodostigma"). They found polysaccharides on the strumae, suggesting that 
77 the structure may provide nutrition to floral visitors as well as a protected site for mating,

78

79

80

81

82

83

84

85

86

87

88

89

90

91

92

93

94

95

96

97

98

99

100

101

102

103

104

105

106

107

108

109

110

111

112

113

114

115

116

oviposition, brooding and larval feeding (Shao \& Xu, 2015). This is consistent with the "food body" hypothesis in Sapranthus (Schatz, 1987) or "nutritious tissues" hypothesis (Gottsberger \& Webber, 2018). Moreover, Shao \& Xu (2015) also introduced a third hypothesis, the "broodsite" hypothesis. The study failed to establish that the observed floral visitors (thrips) are effective pollinators, however.

In this study, paraffin sectioning was undertaken to investigate the anatomy of the corrugations at the base of the adaxial surface of the inner petals, with the aim to testing the alternative hypotheses regarding the function of the corrugations.

\section{Materials \& Methods}

\section{Ethics statements}

The new species reported in this study was collected from Xishuangbanna Tropical Botanical Garden, Yunnan Province, China, which permitted our field work in the Garden. Since this species is currently undescribed, it is not currently included in the China Species Red List (Wang $\&$ Xie, 2004).

\section{Nomenclature}

The electronic version of this article in Portable Document Format (PDF) will represent a published work according to the International Code of Nomenclature for algae, fungi, and plants (ICN), and hence the new names contained in the electronic version are effectively published under that Code from the electronic edition alone. In addition, new names contained in this work which have been issued with identifiers by IPNI will eventually be made available to the Global Names Index. The IPNI LSIDs can be resolved and the associated information viewed through any standard web browser by appending the LSID contained in this publication to the prefix "http://ipni.org/". The online version of this work is archived and available from the following digital repositories: PeerJ, PubMed Central, and CLOCKSS.

\section{Material collection}

The new species has been monitored in Xishuangbanna Tropical Botanical Garden by the authors continuously since 2014. Flowering and fruiting specimens were collected for morphological study. Mature flowers for anatomical study were fixed in FAA ( $70 \%$ alcohol, formaldehyde and glacial acetic acid in a ratio of 90:5:5) for 24 hours and then transferred to store in $70 \%$ alcohol. Leaf materials for DNA extraction were collected and dried using silica gel in the field.

\section{Morphological observations}

Morphological description of the new species was based on careful examination of materials collected. Comparisons with other similar Meiogyne species were based on the existing literature 
117 (van Heusden, 1994; Li \& Gilbert, 2011; Thomas et al., 2012; Johnson et al., 2019) as well as the

118 study of herbarium specimens and digitized images (mainly from HITBC, IBSC, KEP, KUN, PE 119 and SING herbaria).

120 Flower samples in 70\% alcohol were prepared for scanning electron microscopy by

121 dehydration and critical-point drying. Carpels, stamens and pollens were then mounted on metal

122 stubs, sputter-coated with gold, and examined using scanning electron microscope (SEM) as in

123 Xue et al. (2017). Flowers fixed in 70\% alcohol were also dissected for anatomical observations

124 using paraffin sectioning following Xue et al. (2017).

125

126

127

128

129

130

131

132

133

134

135

136

137

138

139

140

141

142

143

144

145

\section{Results}

\section{Phylogenetic analysis}

The seven-region concatenated alignment of the 73 -accesion dataset consisted of 8,923

149 characters. The resultant MP and BI topologies based on the concatenated alignment are similar. The BI tree with both posterior probabilities and MP bootstrap values for each clade is shown as Fig. 1. The new species, Meiogyne oligocarpa, is deeply nested within the Meiogyne clade ( $\mathrm{PP}=$ 1 , MPBS $=92 \%)$. Although these results confirm that the new species unequivocally belongs to the genus Meiogyne, limitations in internal resolution and support preclude any definitive conclusion regarding which species is phylogenetically closest to $M$. oligocarpa.

155

156

\section{Morphological comparisons}


157 Meiogyne oligocarpa has basally and adaxially grooved inner petals (Fig. 2C, D) and the

158 innermost whorl of stamens has expanded connectives (Fig. 3C). These characters are congruent

159 with its placement in the genus Meiogyne. Meiogyne oligocarpa is distinct, however, in having a

160 combination of the following characters: bilobed stigmas (Fig. 2C, 2E, 3A and 4H), up to four

161 carpels per flower (Fig. 2C, 2E), cylindrical monocarps with a beaked apex (Fig. 2F, 2G, 3J and

$1623 \mathrm{~K}$ ), and seeds in two series (Fig. 2H, 3B and 5A).

163 Meiogyne oligocarpa is most similar to M. kanthanensis Ummul-Nazrah \& J.P.C.Tan from

164 Perak, Malaysia and Southern Thailand in its overall flower morphology: both species have

165 large, broad and pubescent petals. The two species differ, however, as follows. Meiogyne

166 oligocarpa has smaller leaves $(12-17 \times 3-4.2 \mathrm{~cm})$ with $10-13$ veins on each side of the leaf,

167 compared with $M$. kanthanensis, which has larger leaves $(16.4-22.6 \times 6.1-9 \mathrm{~cm})$ with 8-10 pairs

168 of veins (Tan et al., 2014; Johnson et al., 2019). Meiogyne oligocarpa has 1-4 carpels per flower

169 with bilobed, sparsely hairy stigmas, whereas $M$. kanthanensis has 3-5 carpels with globose,

170 densely hairy stigmas (Tan et al., 2014; Johnson et al., 2019). The monocarps of M. oligocarpa

171 are cylindrical $(6-8 \times 1.5-2 \mathrm{~cm})$ with a beaked apex, whereas those of $M$. kanthanensis are

172 oblong $(2.7-5.5 \times 2.3-3.2 \mathrm{~cm})$ with a rounded apex (Johnson et al., 2019). A detailed

173 morphological comparison of the two species is summarized as Table 1. Our phylogeny

174 nevertheless indicates that the two species are not closely related (Fig. 1).

175 To conclude, both the molecular and morphological data support the placement of the new

176 species in Meiogyne. It differs from all previously described species, and therefore unequivocally

177 represents a new species.

178

179

180

181

182

183

184

185

186

187

188

189

190

191

192

193

194

195

196

197

\section{Taxonomic treatment}

Meiogyne oligocarpa B.Xue \& Y.H.Tan, sp. nov. (Figs. 2-5)

Type. CHINA. Yunnan Province, He-kou County, the voucher from cultivated plants in Xishuangbanna Tropical Botanical Garden, $21^{\circ} 55^{\prime} 25^{\prime \prime} \mathrm{N}, 101^{\circ} 16^{\prime} 13^{\prime \prime} \mathrm{E}$, alt. 586 m. C. F. Xiao C400733, 15 Oct. 2016 (fl., fr.) (holotype HITBC; isotype IBSC)

Diagnosis. Meiogyne oligocarpa is distinct among Meiogyne species in having a combination of characters, including up to four carpels per flower, bilobed sparsely hairy stigmas, cylindrical monocarps with a beaked apex, and seeds in two series. It is most similar to Meiogyne kanthanensis, but differs in having smaller leaves with more secondary veins, shorter pedicels, stigmas that are bilobed distinctly less hairy, and cylindrical monocarps with a beaked apex. Description. Small trees to $5 \mathrm{~m}$ tall, ca. $4 \mathrm{~cm}$ dbh. Bark grayish. Young twigs green, yellowish puberulent, soon become grayish and glabrous. Petioles 3-5 $\mathrm{mm}$ long, 1-2 $\mathrm{mm}$ in diameter, pubescent; leaf laminas lanceolate, or narrowly elliptic or narrowly oblong, length:width ratio $3.5-4.5,12-20 \times 3-4.2 \mathrm{~cm}$, base slightly asymmetrical, oblique to rounded, apex acute to acuminate, papery, slightly glossy above in vivo, drying dull greyish-green, concolorous beneath, glabrous above, beneath base of leaf margin and midrib pilose, secondary veins sparsely pilose; midrib impressed and glabrous above, raised and hairy below; secondary veins $8-13$ on each side of the leaf, parallel, diverging at $45-60^{\circ}$ from midrib, upturned and gradually diminishing towards apex, connecting to subsequent secondary veins by series of cross veins, and lacking 
198 prominent marginal loops, distinctly raised below; tertiary veins scalariform, prominent abaxially

199 (Fig. 4A). Inflorescences axillary; one flower per inflorescence (Figs. 2B, 4A), greenish to

200

201 yellowish with a strong fruity scent in vivo. Peduncles absent (Figs. 2B, 4A). Pedicels 5-8 mm long, 1-1.5 $\mathrm{mm}$ in diameter, pubescent, with two minute pubescent bracts (Figs. 2B and 4B).

203 Sepals triangular, 7-8 $\times 4-5 \mathrm{~mm}$, pubescent abaxially, glabrous adaxially (Figs. 2B, 2E and 4C); outer petals ovate to lanceolate, $42-50 \times 15-17 \mathrm{~mm}$ in vivo, 30-45 × 9-15 mm when dry, apex acute, grayish pubescent abaxially, glabrous to sparsely villous adaxially (Figs. 2A-C, 4D); inner petals narrower, shorter, cohering when young, 37-48 × 14-17 mm in vivo, 26-38 $\times 9-12 \mathrm{~mm}$ when dry, grayish pubescent abaxially, glabrous to sparsely villous adaxially, basally grooved, often turning reddish when mature, fragrant, margin slightly recurved (Figs. 2A-D, 4E). Stamens with shield-like connective prolongation, elongated in inner whorl, 50-56 per flower, ca. $2 \mathrm{~mm}$ long (Figs. 3C, 3D, 4F, 4G, 5B). Carpels 1-4 per flower, ca. $4 \mathrm{~mm}$ long, with long gray hairs (Figs. 3A, 4H); stigmas shallowly to deeply bilobed, lobes less obvious when dried, sparsely hairy (Figs. 2C, 2E, 3A, 4H); ovules 12-20 per carpel, biseriate (Figs. 3B, 4I, 5A). Fruiting pedicels $3-5 \mathrm{~mm}$ long, $3 \mathrm{~mm}$ in diameter; monocarps 1-3 per fruit, smooth, cylindrical, ca. 6-8 $\mathrm{cm}$ long, $1.5-2 \mathrm{~cm}$ in diameter, apex rostrate, beak $5-10 \mathrm{~mm}$, base contracted into stipe 3-10 $\mathrm{mm}$, densely blackish pubescent, shallowly transversely constricted between seeds when dried (Figs. 2F, 2G, 4J and 4K). Seeds reniform to ellipsoid, up to 20 per monocarp, biseriate, $1.5 \mathrm{~cm}$ long, $1 \mathrm{~cm}$ wide, $8 \mathrm{~mm}$ thick, surface smooth in vivo, wrinkled when dried, raphe raised, endosperm ruminations lamelliform (Figs. 2H-J, 4L). Pollen grains solitary, subspherical, disulculate, $30-40 \mu \mathrm{m}$ in diameter, rugulate (Figs. 3E-G).

Etymology. The specific epithet reflects that the flower has few carpels (1-4) and hence the fruit has few monocarps (1-3).

221

222

Paratypes. China. Yunnan: Ge-jiu City, Man-hao, alt. 700m, 28 Apr. 1994, Ge-jiu Forestry

223 Bureau exped. 94111(KUN); Meng-la County, Men-lun, cultivated in Xishuangbanna Tropical Botanical Garden, 6 Mar. 2006, W.Q. Xiao C400431(HITBC); 25 Nov. 2009, W.Q. Xiao C400583 (HITBC); 23 Mar. 2015, Y.Y. Shao SYY26, SYY27 (IBSC); 13 Oct. 2015, Y.Y. Shao, SYY28 (IBSC, HKU); 5 Aug. 2017, Y.H. Tan \& H.B. Ding XTBG0007 (HITBC); 3 May 2020, B. Yang XTBG0104 (HITBC); 26 Aug. 2020, B. Yang XTBG0181 (HITBC).

227

228 Distribution. Only known from 12 individuals cultivated in Xishuangbanna Tropical Botanical Gardens, Yunnan, China. According to records, it was introduced from He-kou County, Yunnan Province in 2001. In our extensive study of Annonaceae herbarium collections in China, we find only one specimen from Man-hao, Ge-jiu city (Ge-jiu Forestry Bureau exped. 94111, KUN) representing this species. One of the authors, Yun-Hong Tan, has undertaken extensive field survey in He-kou County and adjacent regions, but has failed to locate any wild populations. Primary forests in He-kou have been under severe pressure from agricultural expansion over recent decades, and most unprotected forests at low elevation have been replaced by banana plantations. Additional field surveys are required to locate wild populations of this species in Yunnan. This study highlights the essential role of botanical gardens on biodiversity conservation.

238 Ecology and phenology. In evergreen forests. Flowering and fruiting from March to September. 


\section{Discussion}

\section{Anatomy of inner petal corrugations}

242 The elaborate inner petal corrugations are synapomorphic for Meiogyne. Although these

243 structures have previously often been referred to as "glands" (van Heusden, 1992; Saunders, 244 2010), glandular function has never been confirmed (Xue et al., 2017; Saunders, 2020). Shao \&

$245 \mathrm{Xu}$ (2015) examined the inner petal of Meiogyne hainanensis (as “Oncodostigma") but found no

246 evidence of secretion. It is therefore doubtful whether the corrugations represent true glands,

247 although additional species should be studied.

During our continuous field observations on $M$. oligocarpa, no liquid secretions were observed to form on the inner petals, although strong fruity scents were emitted during anthesis. The anatomical results also indicate that the corrugations are not glandular. The anatomical organization of nectar glands often consist of four distinct tissues (Nepi, 2007; Xue et al., 2017): epidermis; sub-epidermal secretory parenchyma, comprising several layers of small cells with densely staining cytoplasm; ground parenchyma, comprising several layers of larger cells, more loosely packed than those of the secretory parenchyma; and vascular bundles. The anatomy of the inner petal corrugations of M. oligocarpa (Fig. 5C, D), however, consist of an epidermis, several layers of homogeneous parenchyma and a few vascular bundles, and do not differ from adjacent non-corrugated parts of the inner (Fig. 5E) and outer petals (Fig. 5F). The inner petal corrugations are therefore not glandular.

259

Shao \& Xu (2015) studied the corrugations of Meiogyne hainanensis. Based on their observations, they raised two alternative hypotheses regarding the function of the inner petal corrugations, noting that polysaccharides may provide nutrition for floral visitors, and hence the corrugations may function as a "food body" as in Sapranthus (Schatz, 1987), aligned with the "nutritious tissues" hypothesis (Gottsberger \& Webber, 2018).

In our study, we observed numerous curculionid beetles within the flowers of M. oligocarpa, with evidence of gnawing of the petals, although this was present on both the corrugated and non-corrugated parts of the inner petals. We also observed starch and tannin in both whorls of petals (Fig. 5C-F), which may provide food for beetles (Gottsberger \& Webber, 2018). A more detailed histochemical study is nevertheless required, as well as additional field observations on the distribution of gnawing marks to verify the "nutritious tissues" hypothesis.

The second hypothesis raised by Shao \& Xu (2015) is that strumae may provide floral visitors with a protected site for mating, oviposition, brooding and larval feeding, thus functioning as a "brood-site". Although this might represent an example of pollinator brood-site adaptations of petals in Annonaceae, Shao \& Xu (2015) failed to establish that thrips are the effective pollinator (Saunders, 2020). This also requires further study. It would also be

275 interesting to check whether beetle larvae are present on the petals of M. oligocarpa.

276

277

\section{Meiogyne species in China}


278 According to the Flora of China (Li \& Gilbert, 2011), only one Meiogyne species is recorded

279 from China: $M$. kwangtungensis Li, known from only two fruiting collections from Hainan

280 Province. Rainer \& Chatrou (2006) suggest that M. kwangtungensis might be better

281 accommodated within Pseuduvaria or Mitrephora, although its placement in Meiogyne is

282 debatable due to the lack of flowers. Fortunately, with new flowering and fruiting collections

283 recently collected from Hainan Province, we have been able to confirm that M. kwangtungensis

284 should be placed in Pseuduvaria (Q.L. Wang et al., in press)

285 The only currently accepted Meiogyne species in China is M. hainanensis (Merr.) Bân from

286 Hainan Province (Tisang \& Li, 1979; van Heusden, 1994; Rainer \& Chatrou 2006; Xue et al.,

287 2014), although Li \& Gilbert (2011) treated this species as Chieniodendron hainanense (Merr.)

288 Tsiang \& P.T. Li (Tsiang \& Li, 1979). The transfer of Chieniodendron to Meiogyne has been

289 widely accepted (Bân 1973; van Hesuden 1994) and supported in recent molecular phylogenetic

290 studies (Thomas et al., 2012; Xue et al., 2014).

291

292

293

294

295

296

297

298

299

300

301

302

303

304

305

306

307

308

309

310

311

312

313

314

315

316

317

\section{Acknowledgements}

Peer) reviewing PDF | (2020:08:52419:2:0:NEW 26 Jan 2021) 
319 We are grateful to the curators of IBSC, KEP, KUN, HITBC, PE and SING for permission to 320 access their collections. Thanks Dr. Richard Chung and Dr. Saw Leng Guan in KEP for sending 321 type specimen images and leaf material of Meiogyne kanthanensis; Qin Ban in PE for sending 322 specimen photo; Ding-Han Cui for the line drawing; Xiao-Ying Hu for technical assistance with 323 SEM at South China Botanical Garden; Richard Saunders for improving the language of this 324 manuscript; Thomas Couvreur and two anonymous reviewers for the constructive comments to 325 improve this manuscript.

326

327

328

329

330

331

332

333

334

335

336

337

338

339

340

341

342

343

344

345

346

347

348

349

350

351

352

353

354

355

356

357

358

\section{REFERENCES}

Applequist WL. 2012. Report of the Nomenclature Committee for Vascular Plants: 64. Taxon 61: 1108-1117. DOI 10.1002/tax.615019

Chatrou LW, Pirie MD, Erkens RHJ, Couvreur TLP, Neubig KM, Abbott JR, Mols JB, Maas JW, Saunders RMK, Chase MW. 2012. A new subfamilial and tribal classification of the pantropical flowering plant family Annonaceae informed by molecular phylogenetics. Botanical Journal of the Linnean Society 169: 5-40. DOI 10.1111/j.10958339.2012.01235.x

Guo X, Tang CC, Thomas DC, Couvreur TLP, Saunders RMK. 2017. A mega-phylogeny of the Annonaceae: Taxonomic placement of five enigmatic genera and support for a new tribe, Phoenicantheae. Scientific Reports 7: 7323. DOI 10.1038/s41598-017-07252-2

Gottsberger G, Webber AC. 2018. Nutritious tissue in petals of Annonaceae and its function in pollination by scarab beetles. Acta Botanica Brasilica 32:279-286. DOI 10.1590/0102$33062017 \mathrm{abb} 0356$

Johnson DM, Liu M-F, Saunders RMK, Chalermglin P, Chaowasku T. 2019. A revision of Meiogyne (Annonaceae) in Thailand, with descriptions of four new species. Thai Forest Bulletin Botany 47:91-107.

DOI 10.20531/tfb.2019.47.1.13.

Li PT, Gilbert MG. 2011. Annonaceae. In: Wu ZY, Raven PH, and Hong DY, eds. Flora of China. vol.19. Beijing: Science Press \& St. Louis: Missouri Botanical Garden Press, 672713.

Miquel FAW. 1865. Annonaceae archipelagi Indici. Annales Musei Botanici Lugduno-Batavi 2: $1-45$.

Mueller, F.J.H. 1863. Fragmenta phytographiae Australiae, vol. 4, fasc. 25. Melbourne: J. Ferres, Government of Victoria.

Nepi M 2007. Nectary structure and ultrastructure. In: Nicolson SW, Nepi M, Pacini E eds. Nectaries and nectar. Dordrecht: Springer, 129-166.

Nylander JAA. 2004. MrModeltest, version 2. Evolutionary Biology Centre, Uppsala University http://www.abc.se/ nylander/mrmodeltest2/mrmodeltest 2 .html.

Qian LS, Chen JH, Deng T, Sun H. 2020. Plant diversity of Yunnan: Current situation and future. Plant Diversity 42: 281-291. DOI 10.1016/j.pld.2020.07.006. 
359

360

361

362

363

364

365

366

367

368

369

370

371

372

373

374

375

376

377

378

379

380

381

382

383

384

385

386

387

388

389

390

391

392

393

394

395

396

397

398

Rainer H, and Chatrou LW. 2006. AnnonBase: world species list of Annonaceae, ver. 1.1. Available at http://www.annonaceae.org. (accessed on 16 Jul 2020)

Ronquist F, Huelsenbeck JP. 2003. MrBayes 3: Bayesian phylogenetic inference under mixed models. Bioinformatics 19:1572-1574. DOI 10.1093/bioinformatics/btg180.

Saunders RMK. 2010. Floral evolution in the Annonaceae: hypotheses of homeotic mutations and functional convergence. Biological Reviews 85:571-591. DOI 10.1111/j.1469185X.2009.00116.X

Saunders RMK. 2020. The evolution of key functional floral traits in the early divergent angiosperm family Annonaceae. Journal of Systematics and Evolution 58: 369-392. DOI $10.1111 /$ jse. 12645 .

Schatz GE. 1987. Systematic and ecological studies of Central American Annonaceae. PhD Thesis, University of Wisconsin, Madison.

Shao YY, Xu FX. 2015. Development and function of the strumae on the adaxial sides of the inner petals of Oncodostigma hainanense. Plant Science Journal 33: 595-601. DOI 10.11913/PSJ.2095-0837.2015.50595

Swofford DL. 2003. PAUP*. Phylogenetic Analysis Using Parsimony (* and Other Methods). Version 4.0b10. Sinauer Associates, Sunderland, Massachusetts.

Tan JPC, Kiew R, Saw IG, Ummul-nazrah AR. 2014. Three New Species from Gunung Kanthan, a Limestone Tower Karst in Perak, Malaysia. Phytotaxa 177:146-154. DOI 10.11646/phytotaxa.177.3.2.

Thomas DC, Surveswaran S, Xue B, Sankowsky G, Mols JB, Kessler PJA, Saunders RMK. 2012. Molecular phylogenetics and historical biogeography of the Meiogyne-Fitzalania clade (Annonaceae): generic paraphyly and late Miocene-Pliocene diversification in Australasia and the Pacific. Taxon 61:559-575. DOI 10.1002/tax.613006.

Tsiang Y, Li PT. 1979. Annonaceae. In: Tsiang Y, Li PT, eds. Flora Reipublicae Popularis Sinicae. vol. 30. Beijing: Science Press, 10-175.

Turner IM, Utteridge TMA. 2015. A new species and a new combination in Meiogyne (Annonaceae) of New Guinea. Contributions to the Flora of Mt Jaya, XXI. Kew Bulletin 70:27.

van Heusden ECH. 1992. Flowers of Annonaceae: morphology, classification, and evolution. Blumea Suppl. 7: 1-218.

van Heusden ECH. 1994. Revision of Meiogyne (Annonaceae). Blumea 38:487-511.

van Heusden ECH. 1996. The genus Meiogyne (Annonaceae) in New Caledonia: four new combinations. Bulletin du Mus éum d'Histoire Naturelle, Paris, series 4. Section B, Adansonia 18:75-83.

Wang QL, Zhang H, Shao YY, Wang ZN, Xue B. in press. A second species of Pseuduvaria in China: the identity of the enigmatic species Meiogyne kwangtungensis. PhytoKeys.

Wang S, Xie Y. 2004. China species red list. Beijing: Higher Education Press.

Xue B, Thomas DC, Chaowasku T, Johnson DM, Saunders RMK. 2014. Molecular phylogenetic support for the taxonomic merger of Fitzalania and Meiogyne (Annonaceae): 
399 new nomenclatural combinations under the conserved name Meiogyne. Systematic Botany 39:396-404. DOI 10.1600/036364414x680825.

401 Xue B, Liu M-F, and Saunders RMK. 2017. The nomenclatural demise of Oncodostigma

402

403 (Annonaceae): the remaining species transferred to Meiogyne. Phytotaxa 309:297-298. DOI 10.11646/phytotaxa.309.3.15.

405

Xue B, Shao YY, Saunders RMK, Tan YH. 2017. Alphonsea glandulosa (Annonaceae), a new

406 species from Yunnan, China. PLoS ONE 12: e0170107. DOI

407 10.1371/journal.pone.0170107.

408

Xue B, Guo X, Landis JB, Sun M, Tang CC, Soltis PS, Soltis DE, Saunders RMK. 2020.

409 Accelerated diversification correlated with functional traits shapes extant diversity of the early divergent angiosperm family Annonaceae. Molecular Phylogenetics and Evolution 142: 106659. DOI 10.1016/j.ympev.2019.106659 


\section{Figure 1}

Molecular result showing the phylogenetic position of Meiogyne oligocarpa.

Bayesian 50\% majority-rule consensus tree under partitioned models (cpDNA data: matK, $n d h F, r b c L, t r n L-F, n d h F-r p / 32, r p / 32-t r n L$ and $y c f 1 ; 73$ accessions). Numbers at the nodes indicate Bayesian posterior probabilities and maximum parsimony bootstrap values (> 50\%), in that order. 


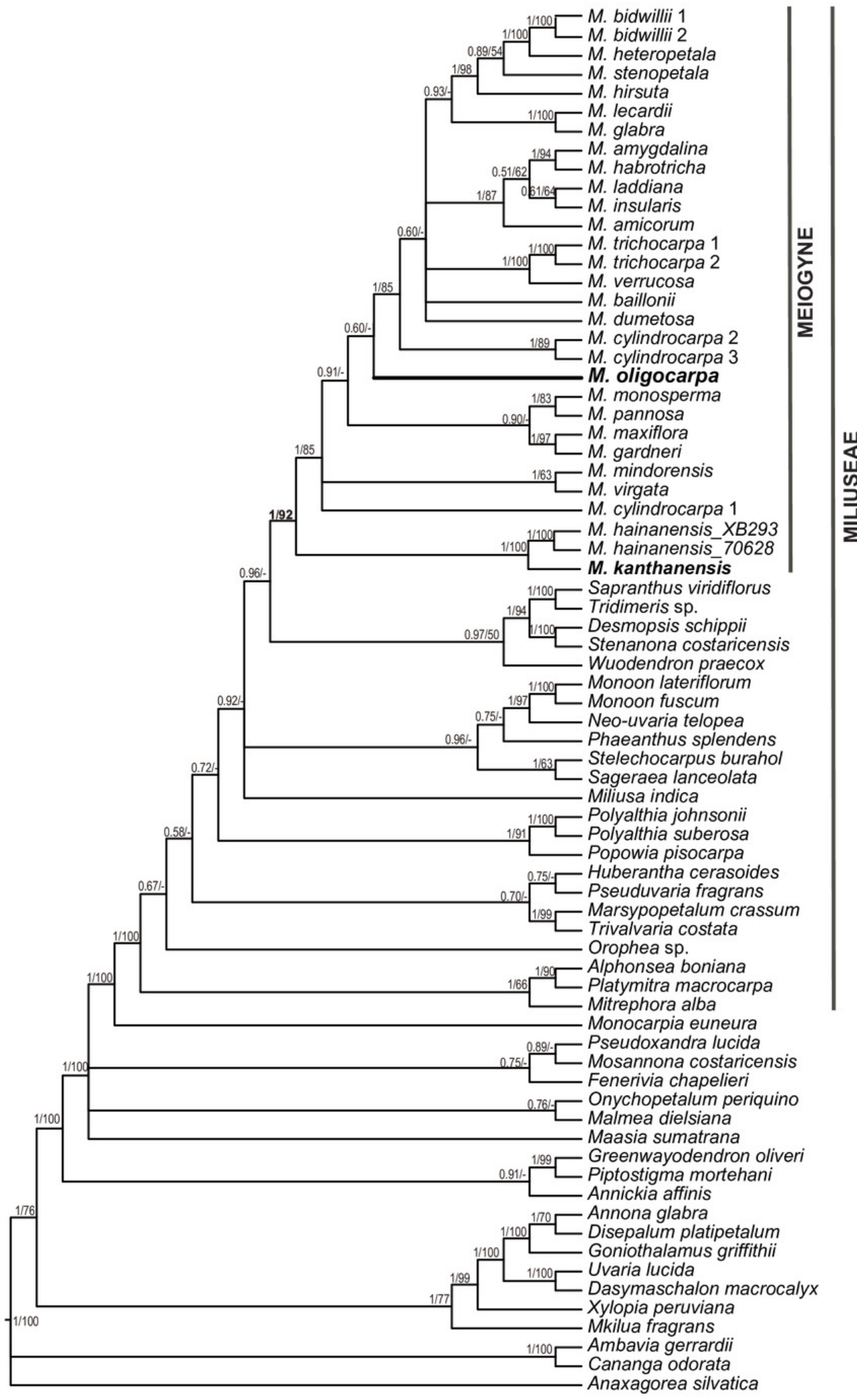

Malmeoideae

Annonoideae

Ambavioideae

Anaxagoreoideae 


\section{Figure 2}

Flower and fruit morphology of Meiogyne oligocarpa sp. nov.

(A) Lateral view of the flower. (B) Abaxial view of the flower. (C) Adaxial view of the flower, showing corrugated structure at the base of the inner petals, and the bilobed stigma. (D) Adaxial and abaxial surface of the inner petals, showing the corrugated structure at the base of the adaxail surface of the inner petals, and the pubescent indumentum at the abaxial surface. (E) Flower with the petals removed, showing the sepals, stamens and stigmas. (F) Fruit with three monocarps. (G) Fruit with one monocarp. (H) Fruit with the pericarp removed, showing the biseriate seed arrangement. (I) Fresh Seed. (J) Dried seeds, showing the raised raphe; and the longitudinal section of the seed, showing the lamelliform endosperm ruminations (B. Yang XTBG0181, HITBC). (A, C, G by Yun-Yun Shao; B, D-F, J by Yun-Hong Tan; H-I by Chun-Fen Xiao). 

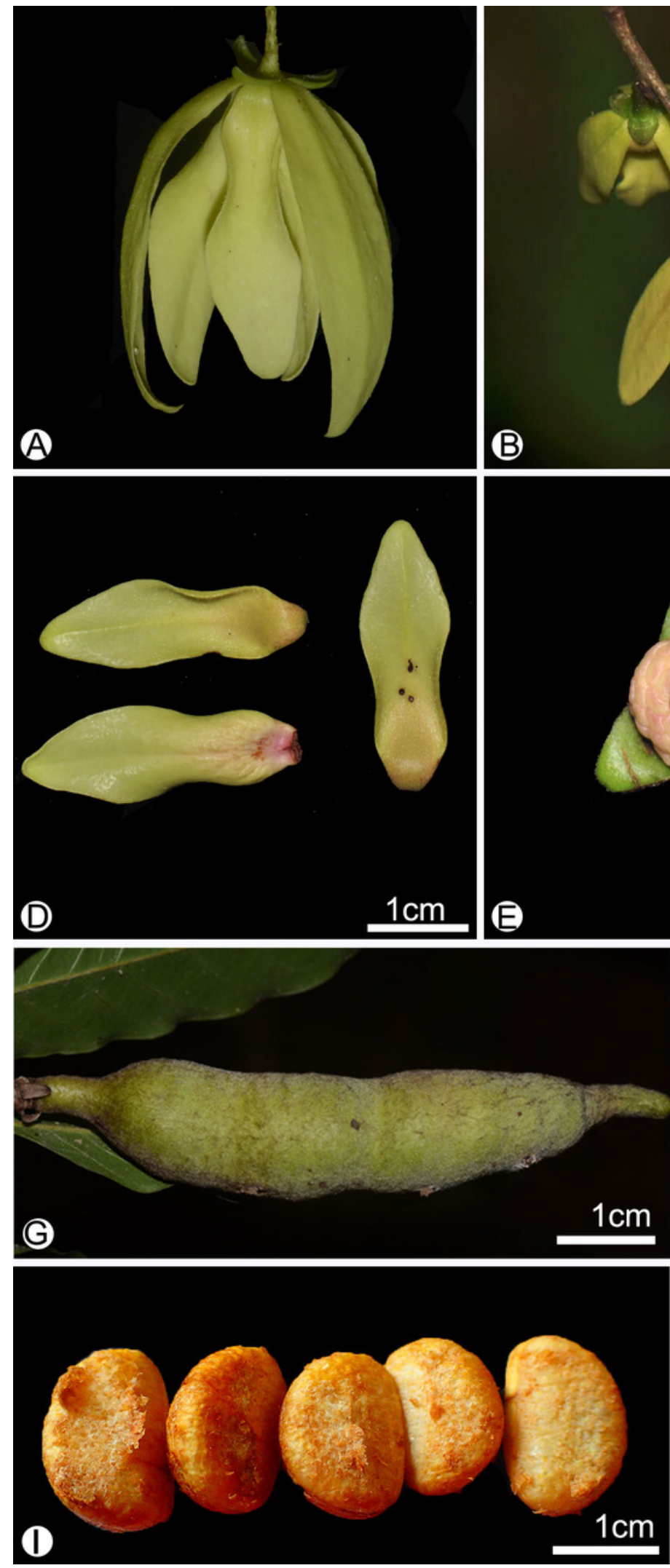

(B)
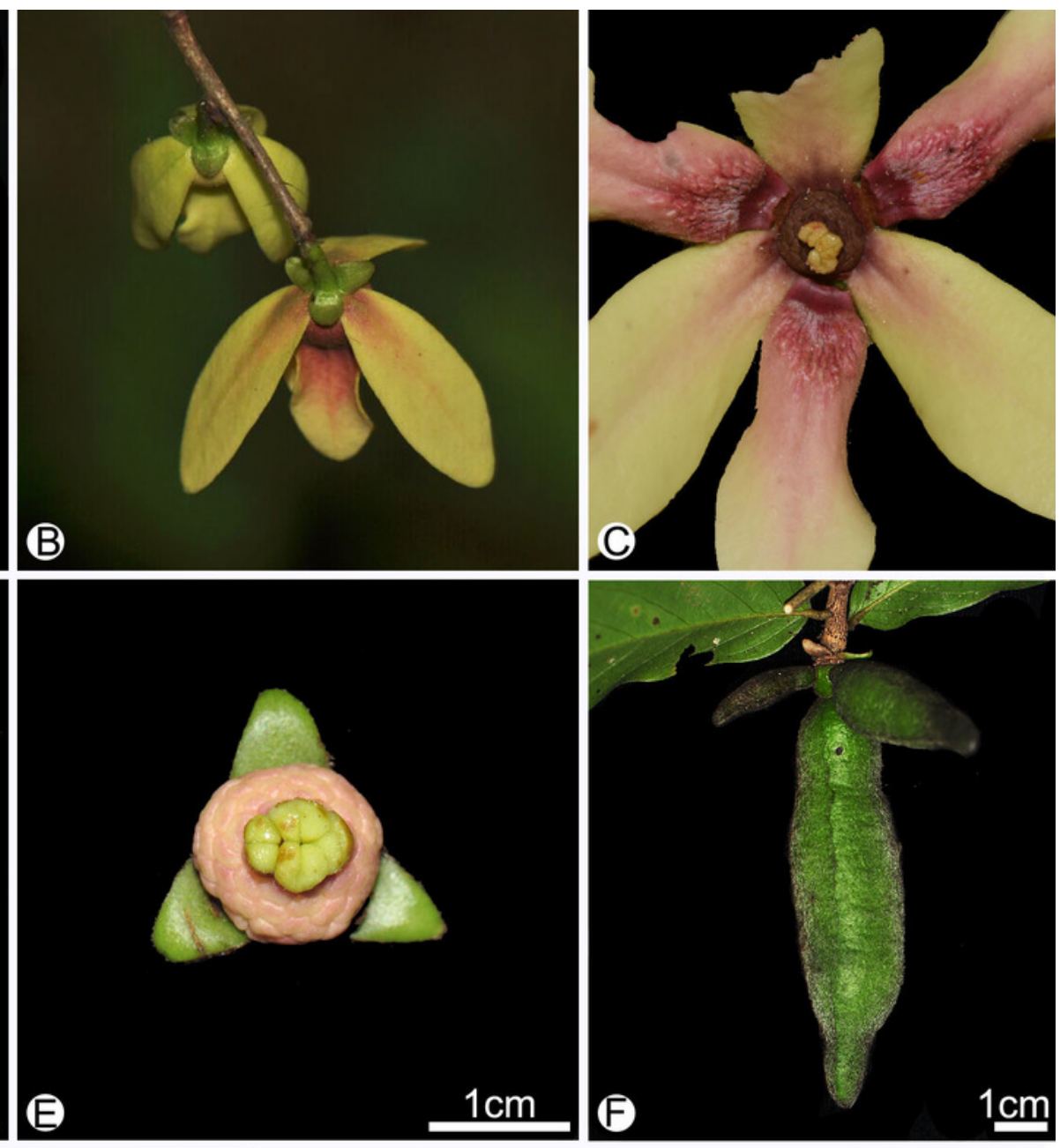

$1 \mathrm{~cm}$
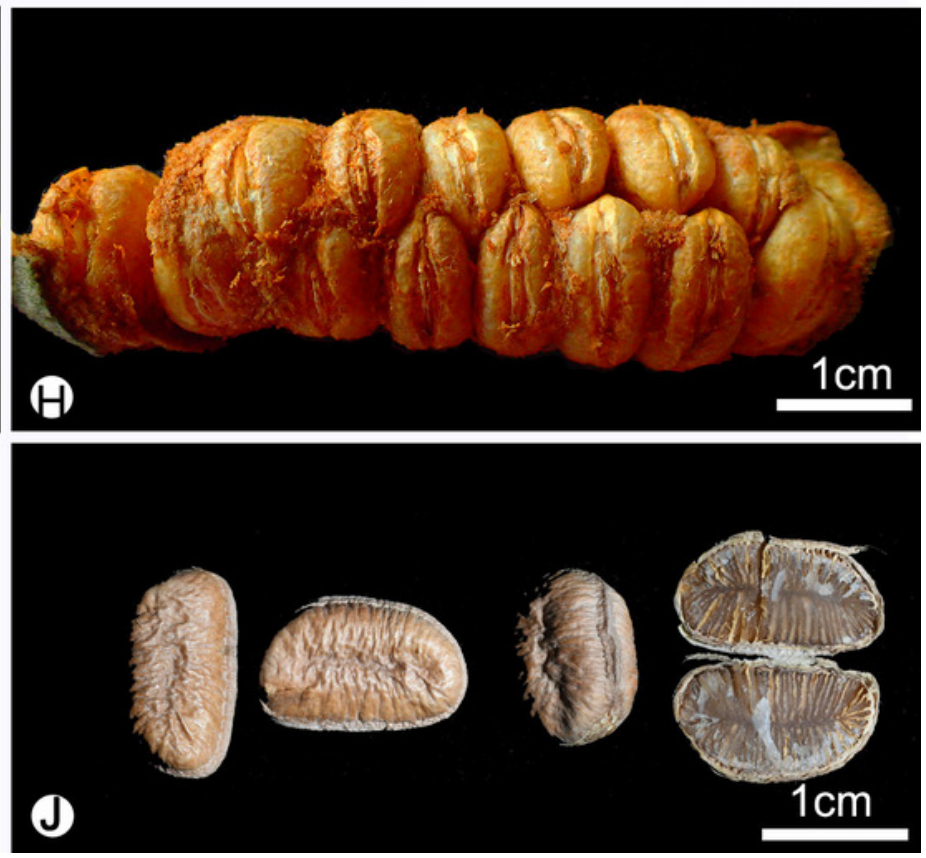


\section{Figure 3}

Morphology of the surface of carpels, stamens and pollens of Meiogyne oligocarpa sp. nov. (scanning electron micrographs).

(A) Carpel, showing the densely hairy ovary and bilobed sparsely hairy stigma. (B) Dissected carpel, showing the biseriate ovules. (C) Innermost stamen, showing the elongated tongueshaped apical prolongation. (D) Outer stamen. (E) Pollen grains. (F) Pollen grain, showing the two germination zones. (G) Rugulate pollen exine ornamentation. (A-G by Yun-Yun Shao). 

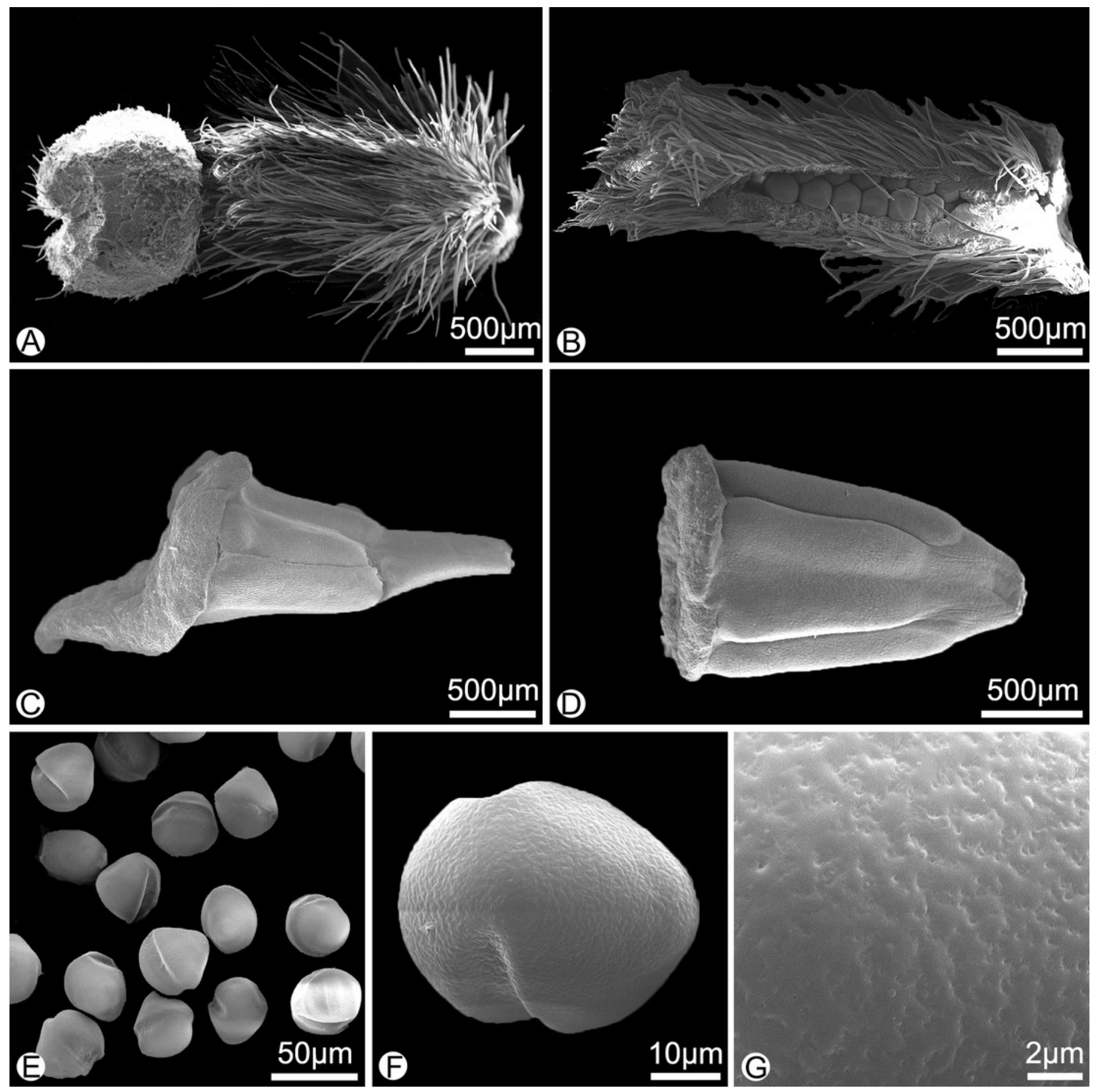

$500 \mu \mathrm{m}$

(D)

$500 \mu \mathrm{m}$

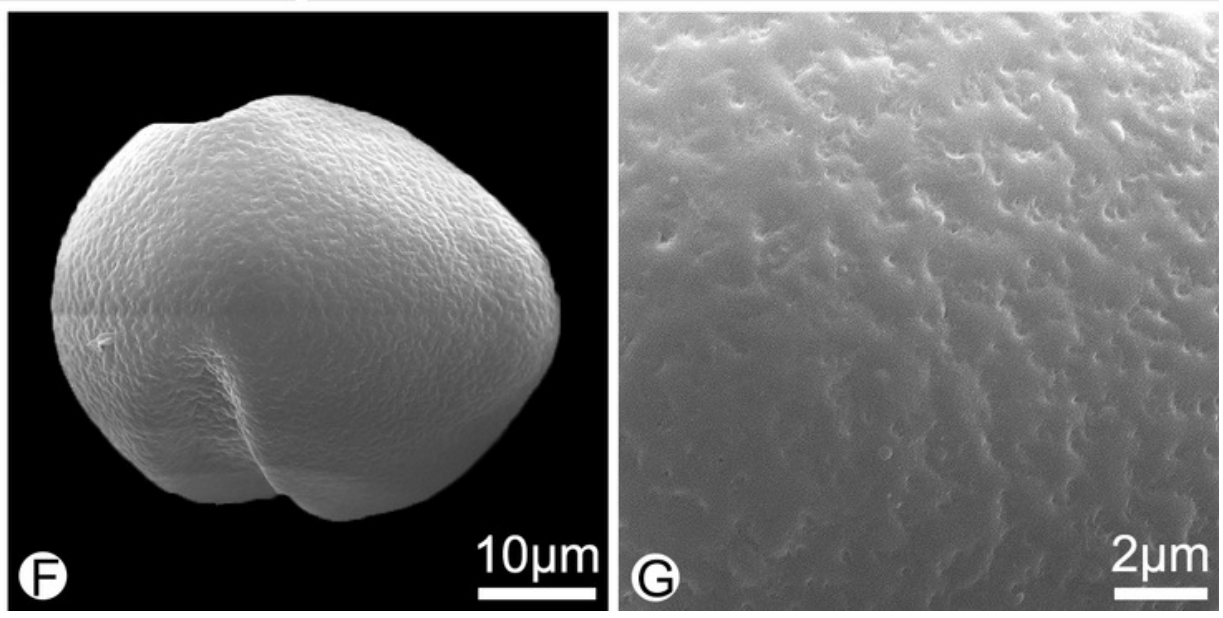




\section{Figure 4}

Line drawing of Meiogyne oligocarpa sp. nov.

(A) Flowering branch. (B) Flower, lateral view. (C) Sepals, ad- and abaxial view. (D) Outer

petals, ad- and abaxial view. (E) Inner petals, ad- and abaxial view; adaxial view showing the corrugations at the base. (F) Innermost stamen, ad- and abaxial view; adaxial view showing the elongated tongue-shaped apical prolongation. (G) Outer stamen, ad- and abaxial view. (H) Carpel, showing bilobed stigma. (I) Carpel, longitudinal section, showing the biseriate ovule arrangement. (J) Fresh fruit. (K) Dried fruit, showing monocarp shallowly transversely constricted between seed. (L) Seed. Drawn by Ding-Han Cui, from C. F. Xiao C400733 (IBSC). 


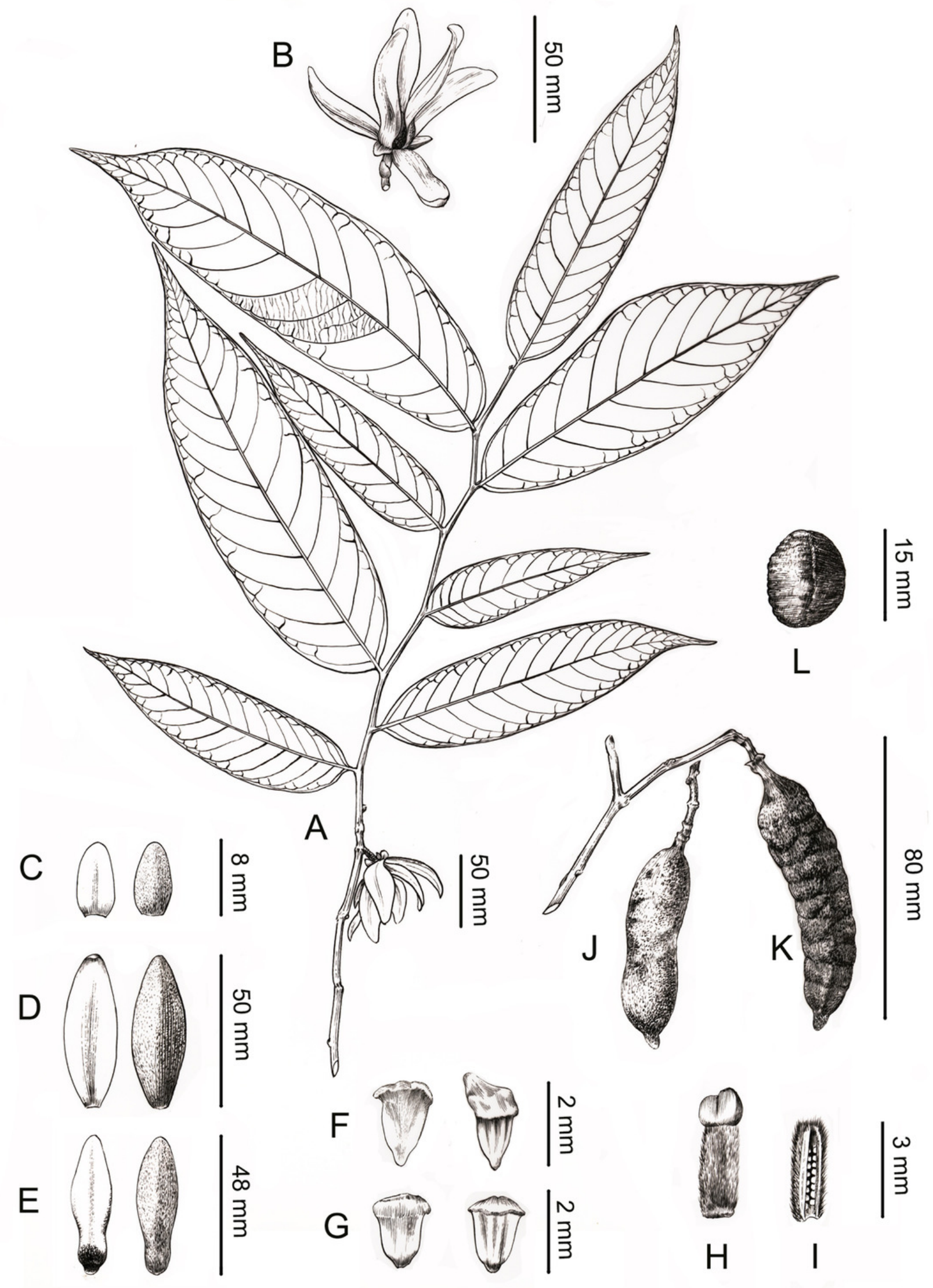




\section{Figure 5}

Anatomical structure of the carple, stamen, inner petal and outer petal (paraffin sections).

(A) Section of the carpel, showing the biseriate ovule arrangement. (B) Section of the stamen, showing the four pollen sacs. (C) Section of the corrugated part of the inner petal. (D) Close-up of the section of the corrugated part of the inner petal, showing many cells containing dark-blue stained starch granules and a few number of cells filled with browncolored tannis mixed with starch granules. (E) Section of the non-corrugated part of the inner petal. (F) Section of the outer petal. (A-F by Yun-Yun Shao). 

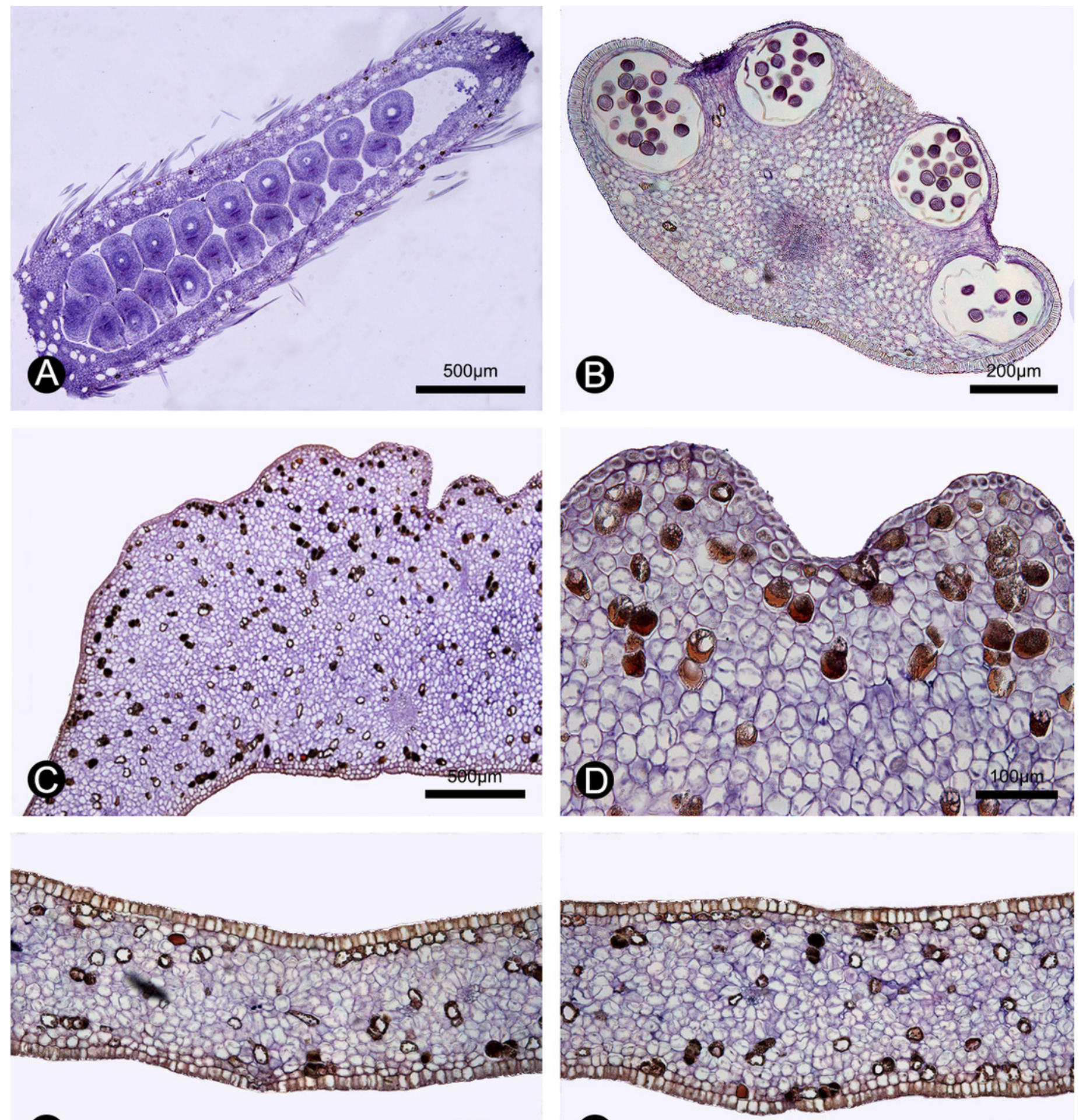

토 


\section{Figure 6}

Morphological comparison of the two Meiogyne species in China.

(A-C) Meiogyne oligocarpa. (A) Leaf, adaxial view. (B) Inflorescence comprising a solitary flower. (C) Fruit, showing one monocarp a beaked apex. (D-J) Meiogyne hainanensis. (D) Leaf, adaxial view. (E) Inflorescence comprising one to several flowers. (F) Flower, top view. (G) Flower with one outer petal removed, showing the globose clavate stigma. (H) Fruit, showing up to eight monocarps with a rounded apex. (I) Monocarp with pericarp removed, showing biseriate seed arrangement. (J) Seed. (A, by Chun-Fen Xiao; B, C, G by Yun-Yun Shao; D by Bine Xue; E, F, H, by Yun-Hong Tan; I-J by Ren-Bin Zhu). 

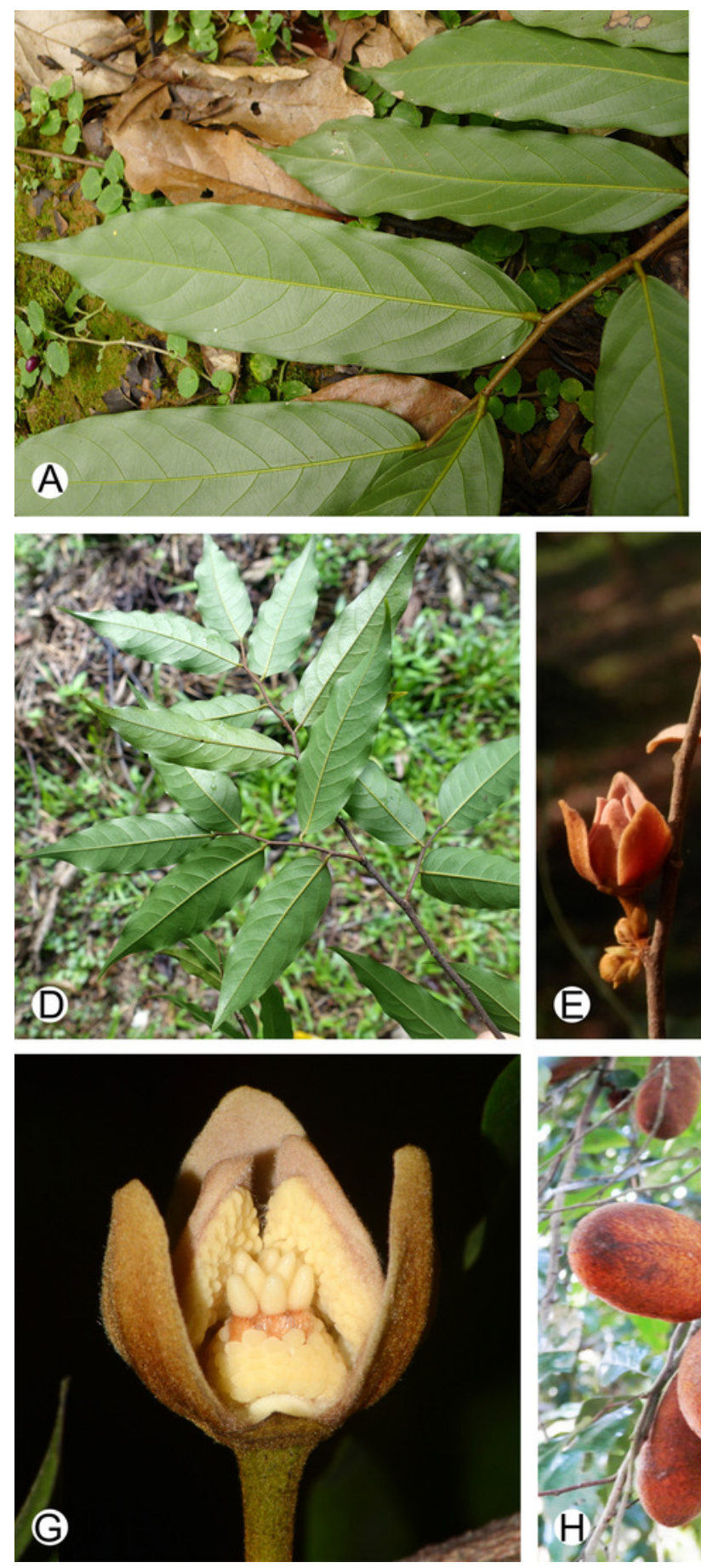

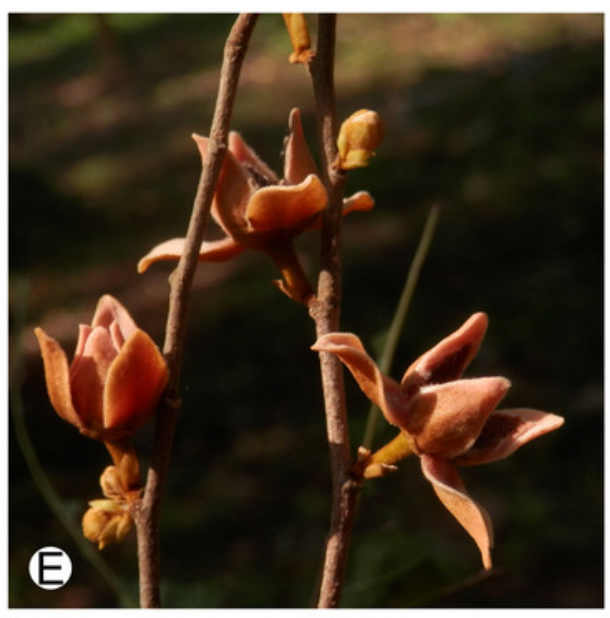

B
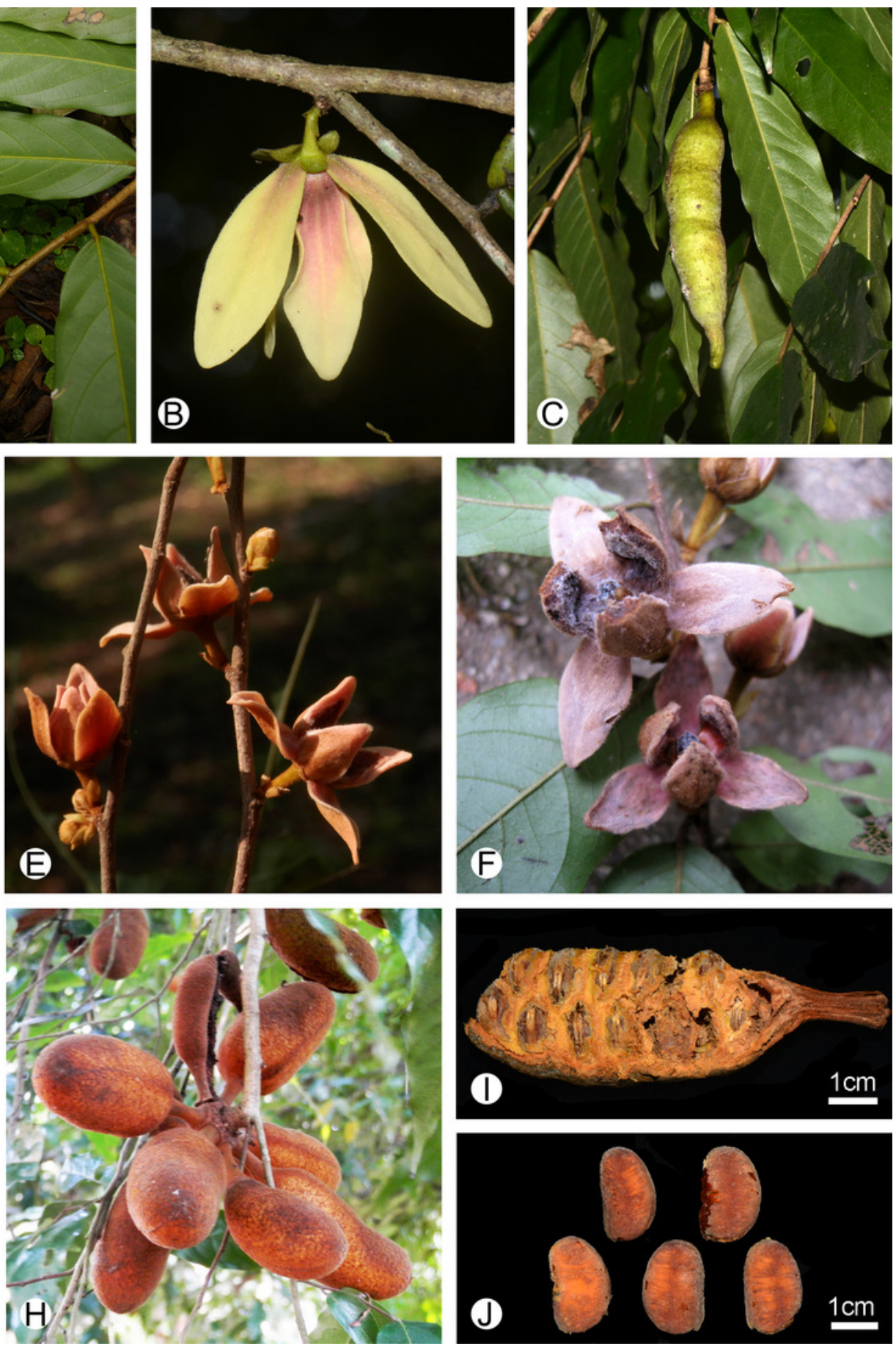
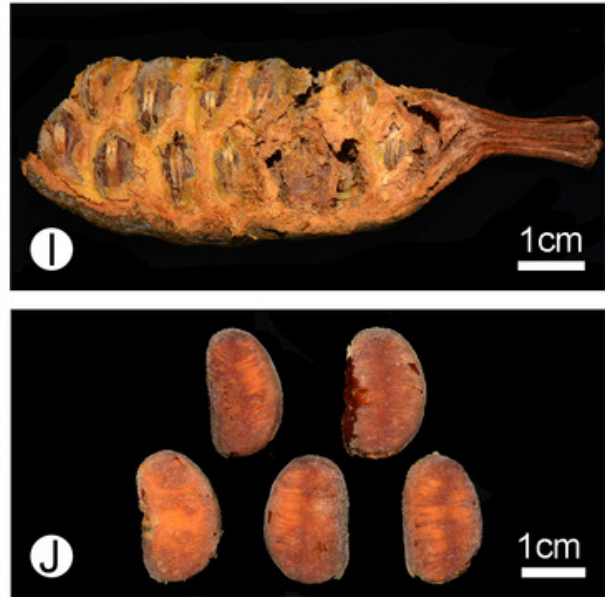


\section{Table $\mathbf{1}$ (on next page)}

Table 1. Morphological comparison between Meiogyne oliocarpa , M. kanthaensis and M. hainanensis. 
1 Table 1. Morphological comparison between Meiogyne oliocarpa, M. kanthaensis and M.

2 hainanensis.

Characters Meiogyne oliocarpa M. kanthaensis $16.4-22.6 \times 6.1-9$

Size of the leaves $\quad 12-17 \times 3-4.2 \mathrm{~cm}$

$\mathrm{cm}$ M. hainanensis

Number of secondary veins on leaf 10-13 pairs

8-10 pairs

6-9 pairs

Size of outer petals when dry $30-45 \times 9-15 \mathrm{~mm}$

$42 \times 13-23 \mathrm{~mm}$

$9-13 \times 5-8 \mathrm{~mm}$

Size of inner petals when dry 26-38 ×9-12 mm

$37-41 \times 15-17 \mathrm{~mm}$

$8-12 \times 5-7 \mathrm{~mm}$

Number of carpels

per flower

1-4

3-5

up to 10

Shape of the stigmas

bilobed

globose

clavate to conical

Indumentum of the stigmas

sparsely hairy

densely hairy

glabrous

cylindrical, with a cylindrical, ovoid or beaked apex, 6-8

Size and shape of $\times 1.5-2 \mathrm{~cm}$ unknown ellipsoid, apex often the monocarps Indumentum of the monocarps

unknown rusty pubescent 